\title{
Current state mapping of the supply chain in engineering procurement construction (EPC) project: a case study
}

\author{
Moh Nur Sholeh ${ }^{1, *}$ and Shifa Fauziyah ${ }^{1}$ \\ ${ }^{1}$ Civil Engineering, Vocational School, Diponegoro University, Semarang 50275, Indonesia
}

\begin{abstract}
Engineering Procurement Construction (EPC) is a construction model that integrated the work between engineering, procurement, and construction. The EPC project is usually applied in petroleum work. One of the important aspects of success key in this project is the supply chain management (SCM). The high level of complexity of work as well as the integration of the construction phase needs to be mapped how the supply chain in this project. This paper used Value Stream Mapping (VSM) method to explain the procurement processes for easier understanding and problem identification. It is illustrated in the procurement process behaviour within a specific period from the total production time. This paper describes a case study performed on EPC 1 Banyu Urip Project. VSM presented real-time data to deliver the processes, material, and any other constraint relevant to the procurement process on EPC projects. Based on a case study on pipe material, the procurement process from upstream to downstream took 21 weeks. It was a waste of time to look for solutions. The recommended solutions use the local vendors, involve suppliers early and provide input into engineering designs, and good communication between supply chain participants.
\end{abstract}

\section{Introduction}

For a long period of time, the poor performance and poor efficiency in construction projects have been confusing the researchers and stakeholders [1,2]. Supply Chain Management (SCM) that has been successfully applied in manufacturing is introduced to construction projects to improve efficiency and reduce waste $[3,4]$. Therefore, the construction project competition among companies has been changed into the competition among supply chains [5]. Practitioners have been aware of this condition and have applied it in their project management [1]. On the other hand, supply chain performance has been measured in many ways with good results $[6,7]$.

Now, one of the contract models that are being used in the project is Engineering Procurement Construction (EPC). In the EPC projects, general contractors including planner sections, material procurement, construction, and operators are selected by the owner. General contractors should take greater risks than conventional projects, so SCM

* Corresponding author: mohnursholeh@live.undip.ac.id 
becomes an important aspect for the general contractor [8]. There are several potential risks in EPC projects such as potential delay in schedules, quality problems, hostile relationships, and disconnected information [9, 10]. This is because EPC projects characteristically have long processes, large scales, and multi-participation. So, how the general contractor can maintain supply chain performance is important.

Thus, there is a need for research to explore the current state mapping of EPC projects. To meet this need, this study adopted a Value Stream Mapping (VSM) model to map out a clear supply chain flow. VSM is a part of lean manufacturing that can reduce waste in the supply chain, beside that VSM can report a reduction of work in the process, performance of the person in completing a work affecting productivity [11-13]. Critical observations and interviewing techniques were used with open-ended questions to understand and draw the processes involved in the value chain of the EPC project.

\section{Theoretical background}

\subsection{Construction supply chain management}

We usually hear that the construction industry is different from other industries in a few ways. For example, the principal of construction projects managed by a construction company mostly does only a small part of the result by means of its own production facilities and personnel $[14,15]$. This indicates that there is something special also in its construction Supply Chain Management (SCM). SCM manages the flows of material, cash, and information, by believing in close project-based engagement and collaboration to future collaboration in strategic partnerships [16]. This close collaboration between these different professionals makes the uncertainty of risk and budget smaller. The advantages of SCM is that it can reduce the waste, for example the performance of construction SCM based on the SCOR model shows $20 \%$ waste can be reduced when measured in the overall value at risk and $10 \%$ waste can be reduced when measured in perfect order fulfilment [17].

Despite the exciting attention, SCM, especially in construction, still shows a lack of efficiency and is not always successfully applied in the project environment [18]. Traditional SCM models are actually projected in terms of process-centric and their transposition on project-oriented work is not done immediately and is not structured yet [19]. So, the implementation of SCM is still continuously researched and innovated towards lean construction [20].

\subsection{Engineering procurement construction (EPC) in the supply chain}

The EPC project can be developed into a complex one-of-a-kind product, which requires considerable human performance and financial commitment [21]. In the Engineering (E) phase, the owner determines a clear need, both in quality and quantity, to be communicated to the builder or contractor. In the procurement $(\mathrm{P})$ phase, the contractor begins the procurement process after receiving technical drawings, specifications and other documents. The contractor starts constructing the facilities available in the construction (C) phase in accordance with the work packages prepared at the engineering phase, and with the use of the equipment and materials available in the procurement phase.

The EPC project in the supply chain that is sourced from the supply and demand network model makes the contractor of EPC project to be the core, it integrates the design subcontractors, construction subcontractors, material suppliers, equipment suppliers, suppliers and machine owners through orders of information, logistics and capital flows (Fig. 1) [22]. 


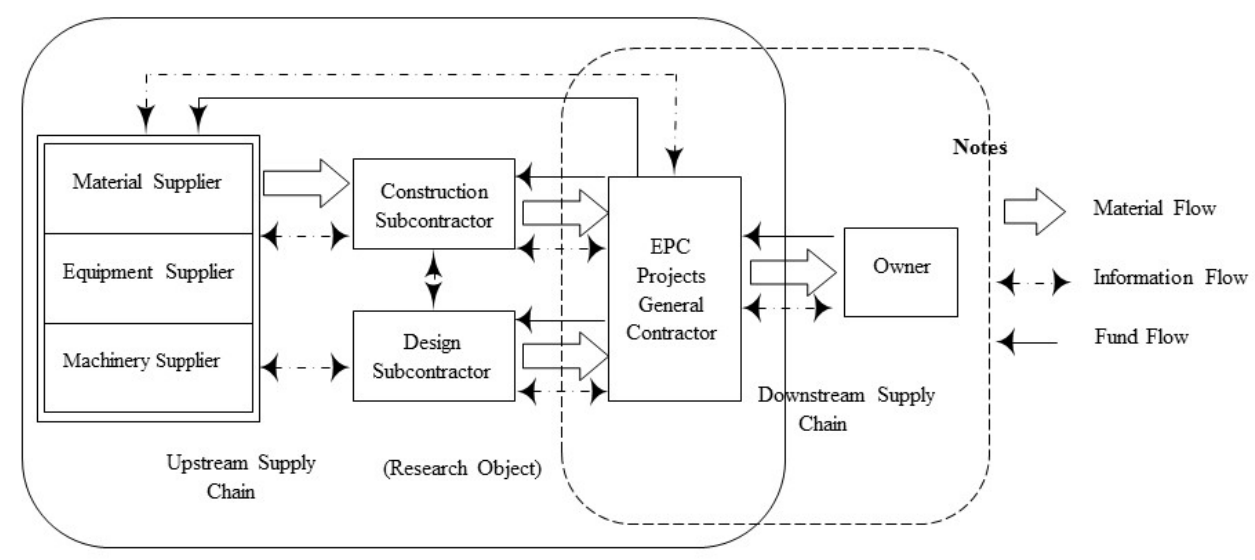

Fig. 1. Construction supply chain structure of EPC projects [8].

\subsection{Current state mapping}

Lately lean construction has attracted much attention in the manufacturing industry including the construction industry [23]. A tool that has been used as a way to run the systematic application of Lean Production, is called Value Stream Mapping (VSM). VSM represents Lean Production's main principle of improvement process to reduce waste [24]. It becomes interesting because essentially waste occurs at every phase of the project life cycle [25]. As we know that the project life cycle phases of the EPC project are engineering, procurement, and construction even commissioning. Previous research has suggested that wastes in interfaces among processes and agents can be identified and possibly reduced by Value Stream Macro Mapping (VSMM) [26]. The study showed that the high potential support lean concepts on construction projects including supply chains.

\section{Methodology}

\subsection{Research method}

To research the possibilities of using VSM model in EPC project, a case supply chain material was selected and exploratory case study project was conducted. The specific object of this study is the materials specified in the EPC project. In VSM model there are five steps to be implemented in the field [27]. First, identify the product or service to the target. Second, draw the conditions in the work field of the current value stream map condition, which shows the process steps, delays, and flow of information needed to complete the product or service. This can be a product stream (from raw materials to customers) or a stream of planning (from concept to implementation). Third, assess the current value stream map condition and look for a process or step that dissipates waste. Fourth, draw a flow map of the value of an impending condition by eliminating where waste existed. The last, do improvements to reach the future condition value stream map. 


\subsection{Data collection and analysis}

The research steps will compare data from interviews and field observations. The author interviewed the project manager or head of logistics to explore the flow of supply chain of material in EPC project. While questionnaires will be filled by the project manager and workers. The questionnaires concern the production lead time and processing time. The compared data will be analysed in quantitative and qualitative. The concept of comparative data is such as Fig 2.

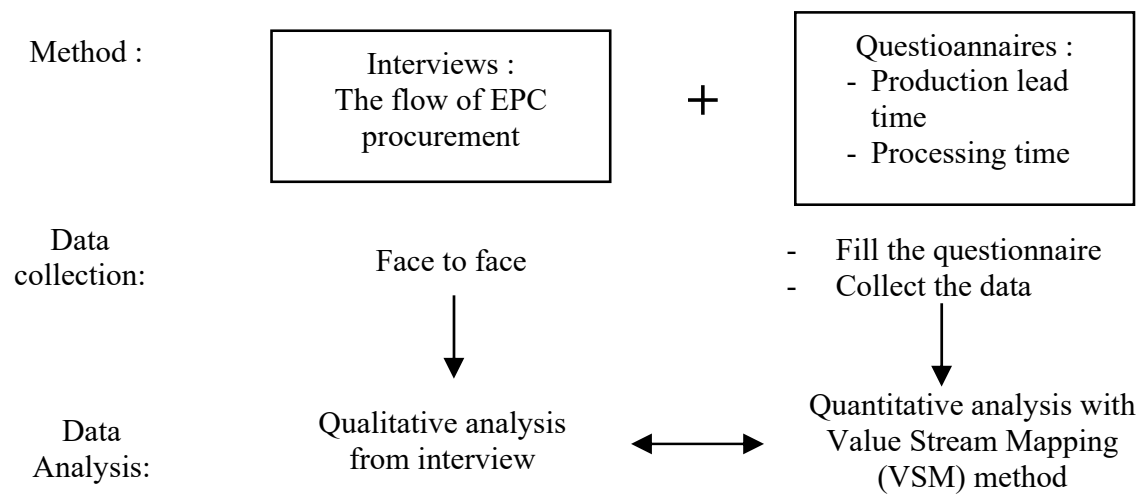

Fig. 2. The concept of research method.

\section{A case study: supply chain in EPC project}

\subsection{Supply chain in EPC project}

The case study was conducted at Banyu Urip Project EPC 1 Production Processing Facilities, located in Bojonegoro, East Java, Indonesia. The owner of this project is SKK Migas and the contractor is PT. Tripatra Engineering - Samsung Engineering Consortium. The project area of EPC is well pads \& off-sites, Central Processing Facilities (CPF) construction consisting of civil work, buildings, mechanical, piping, electrical, instrumentation, and commissioning. In practice, there is no separation of responsibility at each phase of the project life cycle at EPC project.

\subsection{Problems of supply chain}

Procurement of material occurred along the phase of the project, so at the engineering phase, the team of procurement were already working for preparation of procurement. They had already started to register the list of vendors until Purchase Order (PO). So, at the construction phase, the material was ready and can be used without waiting. But the problem that usually occurs at EPC project is a type of material that is unique and large as the pipe of oil refining. For example, the EPC project of this case study is imported from abroad. The contractor should plan where to buy it, when to bring in, and how good process of delivery is because they are the key success of the supply chain.

\subsection{Current state mapping of supply chain}

Authors tested the hypothesis using the Value Stream Mapping (VSM) model. This paper illustrates the flow of procurement of pipe from upstream to downstream. This is because 
the supply chain has the principle of how the clear flow is from the beginning to the end. The overview of the flow of supply chain of pipe supports and current state value stream mapping of EPC projects is as shown in Figure 3 and Figure 4 below:

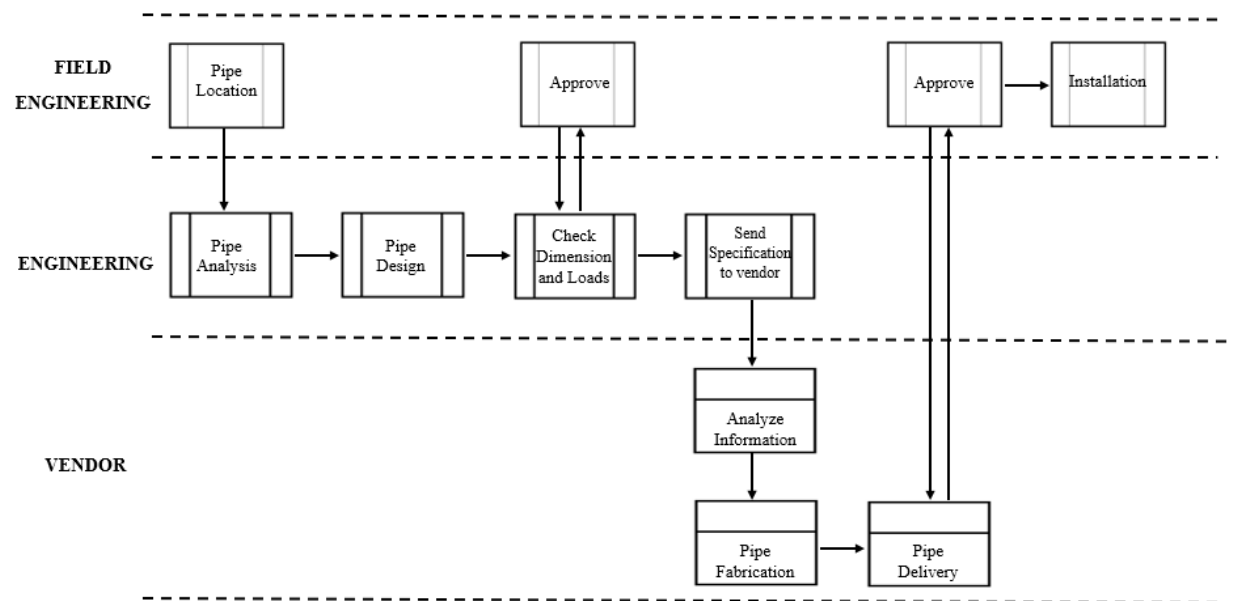

Fig. 3. Supply chain of pipe supports in EPC Project.

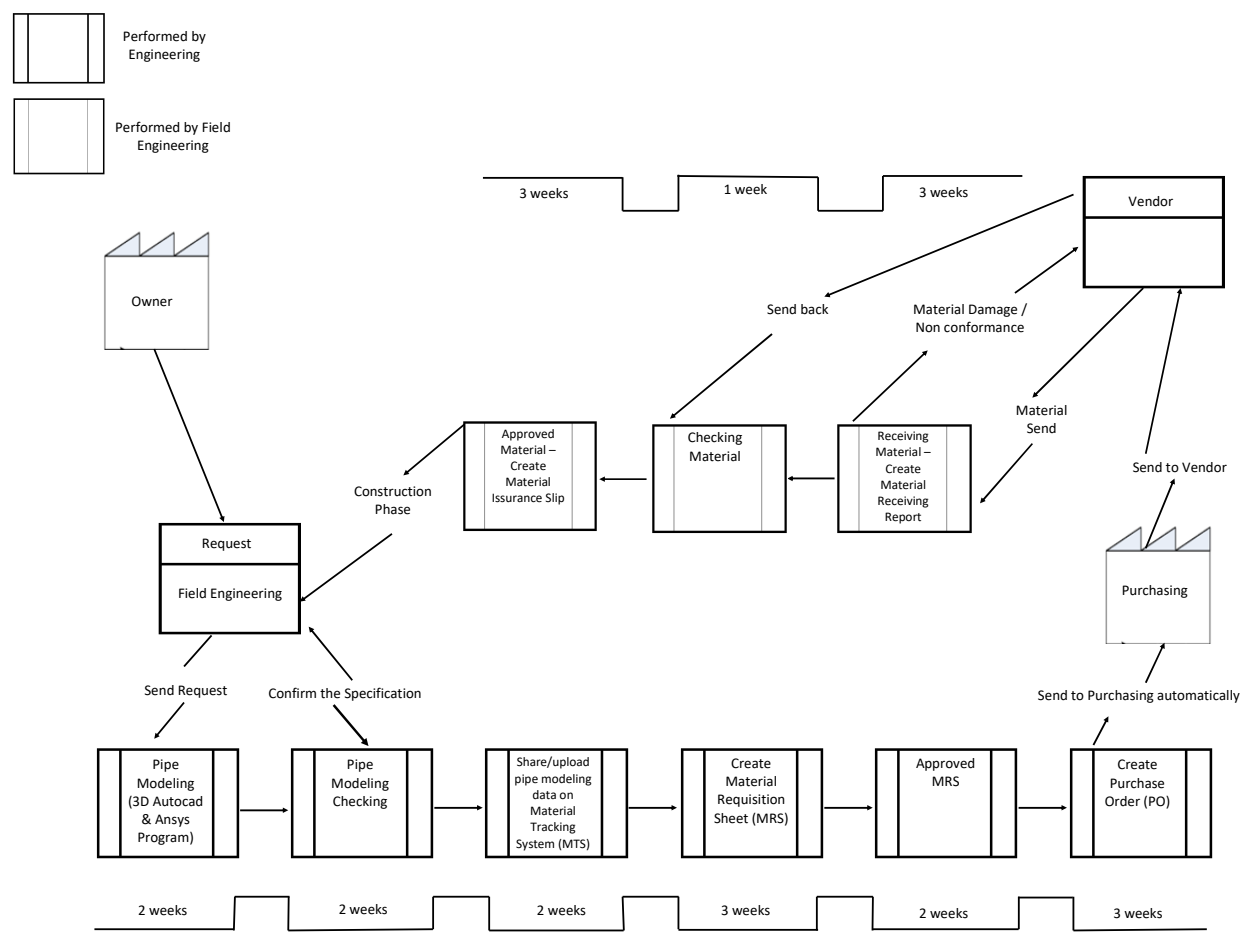

Fig. 4. Current state value stream mapping.

A map of the pipe supply chain for EPC Project is shown in Figure 3. This map includes the work of the engineering, field engineering and vendor. In this structure, the engineering is in charge of piping designing and calculating, the field engineering is in charge of adjusting of conditions in the site to the owner's wishes and the vendor is in charge of providing materials and fabricating them. EPC project at Banyu Urip is taken as case study, it explained how the VSM was used to figure graphically the flow of pipe procurement. 
VSM also includes tasks represented by the engineering, field engineering and vendor. Before drawing the VSM map, value of time has to be defined at the engineering team level, the field engineering team level and the vendor team level. This is done to find which activities add value and which do not.

A current state value stream mapping of the pipe supports is shown in Figure 4. This map illustrates the value stream of pipe support starting from design to application to the site. It represents linked task boxes with arrows in between. In this case, under the task boxes representing the time of a pipe support will be in process from request until delivery to the site. The time in the VSM is a week, considering that each week conforms to 50 working hours per person. The lead times in each task box was determined using three sources of information. The researchers asked engineering, field engineering and vendor organization. It was very difficult to get identical data on other projects. The data provided here are approximate times, validated by several practitioners, vendors and literature, for each supply chain task. The VSM explains that pipe procurement needs from 21 weeks to flow through the phase completely. One reason for values of the duration is the variety and complexity of the design, detailing and delivery as shown in Figure 4.

\section{Discussion}

The aim of this study was to map the current state mapping of the supply chain in EPC by case study. Based on the results of the case study above, there are some interesting things that can be discussed. The procurement of pipe that needs 21 weeks to flow through the phase completely is too long. The contractor should be able to accelerate the time again. The alternative innovation that can be considered are to use the local vendors, involving suppliers early, and making good communication between supply chain participants. Use local vendors during the EPC project in the case study often takes the vendors abroad, especially the pipes material. It is rather difficult but with a strong cooperation of local vendors with good specification of materials, this concept can reduce the duration of procurement of pipes material.

The second consideration involves suppliers early in the design and develop supplier alliance. We know that EPC project is one of design and build project type that integrates from the beginning to the end of the project phase. With the large scale of the project and all is designed by contractor, it is necessary to involve other parties in the design phase. One of important parties is the supplier. The advantages of bringing the suppliers earlier are that suppliers have direct understanding of the project requirements early and are able to manage their own supply chain better. The third is to improve communication and coordination between supply chain participants. Effective communication between different departments in-house is a common difficulty for engineering firms. Industry practitioners explained that $15 \%$ of engineering designs have some mistakes [28]. Moreover, some suppliers who worked in this EPC project were international suppliers.

Based on discussion with the respondents and seeing the current state mapping, there are three aspects that need to be applied to lean construction. Although the procurement can be done more quickly, the contractor needs to check how the quality and impact of the costs. Likewise, when the pipes come faster, whether the warehouse is ready or not. With the amount of big and diverse materials, warehouses must be really well managed.

\section{Conclusions}

This paper has illustrated some of the complexities presented in construction supply chain by presenting the case of pipe supports used in EPC project. It also has demonstrated the 
current state mapping that is very valuable to improve the supply chain performance in EPC projects. Based on a case study on pipe material, the procurement process from upstream to downstream takes 21 weeks. This is a waste of time to look for solutions. Some effort to improve the performance of supply chains is not easy. In addition, to map the current state, this paper also presents considerations for different supply chain participants especially from contractor to reduce the waste of time. Therefore, there are some views of supply chain improvement that need to be applied and certainly still need a lot of studies. Such views are (1) using the local vendors, (2) involving suppliers early and providing input into engineering design, and (3) making good communication between supply chain participants.

Beside illustrating the current state mapping of EPC project, this paper has a significant number of research opportunities to be explored. The viewpoint of the supply chain from the supplier and other stakeholders are very interesting to be analysed again. It is to see the full information of supply chain from upstream to downstream. Besides that, the adaptation and implementation of the value stream mapping in a different material, such as steel and machines, should be further analysed. The additional supply chain improvements can be added from the analysis.

\section{References}

1. R. Vrijhoef, L. Koskela, Eur. J. Purch. Supply Manag., 6 169-178 (2000).

2. L. Bankvall, L.E. Bygballe, A. Dubois, M. Jahre, Supply Chain Manag., 15 385-393 (2010).

3. A. Akintoye, J. Main, Eng. Construct. Architect. Manag., 14 597-617 (2007).

4. M.A. Wibowo, M.N. Sholeh, Procedia Engineering, 125 25-31(2015).

5. X. Xue, Y. Wang, Q. Shen, X. Yu, Int. J. Proj. Manag., 25 150-157 (2007).

6. M.A. Wibowo, M.N. Sholeh, 2nd International Conference on Civil Engineering Research 2016, Sepuluh Nopember Institute of Technology.

7. B. Ritchie, C. Brindley, Int. J. Oper. Prod. Man., 27 303-322 (2007).

8. H. Ke, Z. Cui, K. Govindan, E.K. Zavadskas, Eng. Econ., 26 349-363 (2015).

9. P. Erik Eriksson, Supply Chain Manag., 15 394-403 (2010).

10. N. Ishii, Y. Takano, M. Muraki, Int. J. Proj. Manag., 32 519-528 (2014).

11. D. Seth, N. Seth, D. Goel, Int. J. Manuf. Tech. Manag., 19 529-550 (2008).

12. F.A. Abdulmalek, J. Rajgopal, Int. J. Prod. Econ., 107 223-236 (2007).

13. D. Seth*, V. Gupta, Prod. Plan. Control, 16 44-59 (2005).

14. A. Segerstedt, T. Olofsson, Supply Chain Manag., 15 347-353 (2010).

15. V. Bychkov, M. Faessler, R. Geyer, N. Gorbacheva, Y.V. Gousakov, C. Ilgner, Part. Nucl. Lett, 111 64-73 (2002).

16. E. Papadonikolaki, R. Vrijhoef, H. Wamelink, Management, 631640 (2015).

17. M.A. Wibowo, M.N. Sholeh, H.S. Adji, Procedia engineering, 171 185-190 (2017).

18. L.-E. Gadde, A. Dubois, J. Purch. Supply Manag., 16 254-263 (2010).

19. W.J. O'Brien, K. London, R. Vrijhoef, ICFAI J. Oper. Manag., 3 64-84 (2004).

20. S. Duarte, V. Cruz-Machado, Int. J. Manag. Sci. Eng. Manag., 10 20-29 (2015).

21. K. Yeo, J. Ning, Int. J. Proj. Manag., 20 253-262 (2002). 
22. S. Pryke, Construction supply chain management: Concepts and case studies, John Wiley \& Sons, (2009).

23. H. Yu, T. Tweed, M. Al-Hussein, R. Nasseri, J. Cons. Eng. M., 135 782-790 (2009).

24. F. Pasqualini, P.A. Zawislak, 13th International Group for Lean Construction Conference: Proceedings, International Group on Lean Construction, 117 (2005).

25. M.A. Wibowo, N.U. Handayani, A. Nurdiana, M.N. Sholeh, Adv. Sci. Lett., $232633-$ 2635 (2017).

26. P. Fontanini, F.A. Picchi, Proceedings of the 12th Annual Conference of the International Group for Lean Construction (IGLC-12), Elsinore, Denmark, 3-5 (2004).

27. M. Rother, Toyota kata, McGraw-Hill Professional Publishing, (2009).

28. R.J. Arbulu, I.D. Tommelein, Proceedings IGLC, 183-185 (2002). 